\title{
Why policy needs history (and historians)
}

\author{
VIRGINIA BERRIDGE* \\ Professor of History and Director of the Centre for History in Public Health, London School of Hygiene and Tropical \\ Medicine, University of London, London, UK
}

\begin{abstract}
Policy makers like the idea of new initiatives and fresh starts, unencumbered by, even actively overthrowing, what has been done in the past. At the same time, history can be pigeonholed as fusty and antiquarian, dealing with long past events of no relevance to the present. Academic historians are sometimes bound up in their own worlds. The debates central to academe may have little direct relevance to the immediate concerns of policy making. The paper argues that history, as the evidence-based discipline par excellence, is as relevant as other approaches to evidence-based policy making. Case studies can show us the nature of that relevance. How to achieve influence for history also needs discussion. The relationship is not straightforward and will vary according to time and place. History is an interpretative discipline, not just a collection of 'facts'. The paper discusses how historians work and why it is important for policy makers to engage, not just with history, but with historians as well. Historians too need to think about the value of bringing their analysis into policy.
\end{abstract}

Submitted 1 April 2017; revised 19 May 2017; accepted 1 July 2017

In this paper I will reflect on the opportunities and also some problems of 'thinking in time' alongside non-historians, a phrase which comes from Neustadt and May's book of the uses of history for decision makers (Neustadt and May, 1986). Some historians have been concerned that such relationships bring with them a new 'Whig history' or 'presentism'. By 'Whig history' historians mean the type of history used by the English Whig party in the 18th century, when all history was seen as leading to the high point of the present day. Presentism is what all historians seek to avoid: it means writing history from the vantage point of present day issues and only informed by that perspective. In making our work relevant to non-historians and to policy makers do we lose purchase and standing as historians? The views of historians in the United Kingdom on this issue have changed in the last decade or more. For professional historians working in history departments, the reference

\footnotetext{
*Correspondence to: Virginia Berridge, Professor of History and Director of the Centre for History in Public Health, London School of Hygiene and Tropical Medicine, University of London, 15-17 Tavistock Place, London WC1H 9SH, UK. Email: virginia.berridge@lshtm.ac.uk
} 
point was always other historians and their research. The model was that of the individual historian working alone or with a research assistant. But now the model has moved towards more team working and a greater concern to have 'impact' in some way. Health history in particular has been affected by these developments. The demands of funders and of government research assessment have brought this about (Results \& Submissions: REF 2014, 2017). The aim of this paper is to survey the recent rise in interest; to examine some misconceptions about history; to give examples of its utility; examine the role of other disciplines and different political cultures; and finally to analyse how 'impact' may be achieved.

\section{Recent initiatives for history and policy}

The formalisation of a role in policy making for history is not a totally novel development. One can see this as part of the general rise of 'evidence' in policy making since the 1970s and 1980s, which has had a particular impact in the health arena (Berridge, 2005). This has also led to a revival of the role of history in policy, an interest which originated outside the health field. The formation of the Institute for Contemporary British History in the early 1980s at the Institute for Historical Research, part of the University of London, pioneered the 'witness seminar' as a means of obtaining a group oral history of key events in the recent past. A further development has been the History and Policy partnership and website, which has attracted much attention. It has provided policy briefings based on historical analysis; there have been seminars for civil servants in different government departments (History and Policy, 2016). History has fed in from other directions. Number 10, the Prime Minister's headquarters, has a group of historians who give regular seminars and a historians' section on its website with historical comment although not usually on very current issues (GOV.UK, 2017b). Some research initiatives on policy have incorporated an historical perspective. The RELU initiative (Rural Economy and Land Use programme) saw a veterinary historian temporarily located within a government department and fully engaged in policy advice. The civil service has a Policy Lab which draws on historians among other disciplines to inform potential new directions in policy. Historians give evidence to Commons committees. The Parliamentary Office of Science and Technology (POST) has a Wellcome Trust supported scheme which allows early career historians to be seconded in order to produce an historical briefing on an area of policy interest.

The History Centre at the London School of Hygiene and Tropical Medicine is located within a health institution and its work in this area provides an illustration. A Centre research fellow was seconded to produce a POST briefing on disability and its history. Members have provided policy briefings for History and Policy. The Centre was funded to organise seminars bringing together historians, social scientists and policy makers which have led to policy briefings, including one on alcohol policy (Centre for History in Public Health, 2014). 
It has participated in the production of timelines for the Health Foundation, a funding body, and recently produced an historical analysis for the All Party Group on Health (Berridge and Mold, 2016). The government initiated Foresight initiatives, 20 year forward, looks at policy directions in particular areas, have also included historians. Tim Hickman and I were commissioned to contribute to the Foresight initiative on psychoactive substances (Berridge and Hickman, 2007). Such examples could be multiplied; history is far from moribund as a policy science. In addition, there is a growing published literature on the relationship between history and policy which examines, analyses and in some cases, theorises the relationship (Porter, 1981; Berridge, 2008; Tosh, 2008; Berridge, 2010; Guldi and Armitage, 2014; Green, 2016).

\section{Misconceptions about history}

Despite all this activity, there have been full frontal attacks on the utility of history. One such came in an editorial published in 2014 in the Lancet, written by its editor, Richard Horton, which caused outrage among medical historians (Horton, 2014). It claimed "Most medical historians...have nothing to say about important issues of the past as they might relate to the present. They are invisible, inaudible, and, as a result, inconsequential" (Horton, 2014). Horton had apparently forgotten that even his own journal quite often published historical pieces (in a section called 'The Art of Medicine'). These were framed specifically to deal with issues of policy interest or of interest to a medical and health readership.

History has to struggle against many such misconceptions. To some, it is 'just description', just one 'fact' after another without recognisable analysis. To others (often the same people), it is a discipline which can be practiced by anyone. An historical allusion can be light relief in an article dealing with the present. Sociologists and other social science disciplines are known to use history in a cavalier way, making huge generalisations about the past, unsupported by detailed historical research. Or an historical example can be plucked out of the air because it seems to confirm a general line of argument. One of the purposes of this paper is to argue that history is best done by historians in the lead; other disciplines should investigate what the profession has to say before using it for their own purposes.

It may seem over simplification to write about how historians do history and in fact the discipline does not write a great deal about methodology, much loved by other disciplines. There are primary sources, the material left by people who lived in the past and secondary sources - the books and articles written by historians based on those primary sources. There is a range of documentary sources (newspapers, state and local government papers); archival material, for example, in the British National Archives; or oral history sources ranging from life history to witness seminars. Social media and film are two more recent sources with which historians are now engaging. 
The historian's role is to uncover the sources, to assess them against each other and to blend them into a coherent analysis and interpretation. Historians usually go beyond the secondary and 'grey' literature relied upon by the social sciences. In fact, these disciplines often do not realise that such archival sources exist, in particular if they are not available online. The interpretation derived from the sources is never static in history and each generation rewrites its history. Historical truth is the existing consensus among historians based on corroboration from the sources.

This is a key point about history which is often unappreciated by a non-historical readership or by the non-historian users of history. Social science disciplines such as political science, sociology or economics are of course themselves theoretical and interpretative. But history is often seen by non historian users as untheoretical and without an interpretative base. It is 'just description', the extraction of 'facts' or 'secrets' from 'those dusty archives', never before used (here I am using oft-repeated stereotypical ways of writing about history by non-historians). It is this perception which underpins the widespread disdain for historians (as distinct from history) evinced by other disciplines and which has led to the belief that anyone can be an historian. It is in fact a profoundly interpretative discipline where knowledge and understanding is advanced through the interplay of interpretation of events based on the reading of multiple sources. The lack of understanding of history as interpretation leads to misunderstanding and misuse of history by non-historians. I am regularly invited to referee articles where a non-historian using historical data will proceed quite unaware of what has already been published by historians and of the historiography - a key starting point for any historical paper as a survey of pre-existing interpretation. Non-historians often use the material extracted by historians through their research - for example using quotations from primary sources which they have not accessed themselves, but they do not attribute or acknowledge the interpretation developed by the historian. Building on what has gone before - to support, supplement, oppose or critique interpretation - is axiomatic in historical work. This basic point is generally unappreciated by non-historians who mine historical work, seemingly unaware of its interpretative stance.

\section{Case studies of history and policy}

Two case studies show how historians can be involved in policy issues: the role and location of public health and the issue of devolution and integration in health services; and alcohol and Britain as a 'hard drinking society'.

\section{Public health, its role and location and the issue of devolution and integration in health services}

From the 1970s the 'public health function' in the United Kingdom - specialists and services - was located within the NHS and public health doctors (which they 
mostly were) were termed 'consultant community physicians'. Recently this function has moved into local government and operates through local elected councils. Drug and alcohol treatment, not historically part of public health, also moved over at the same time. There is also within policy currently a desire for devolution to the big cities and regions in the north-most notably in the DevoManc initiative which is devolving control of services in the Greater Manchester region to local control and potentially bringing health and social services together.

There is a history here. This local government base was the location of public health officials in the period from the 19th century up to the 1970s. There has been an awareness in the public health profession (or at least among the older members) that they are what might be called 'coming home' - but little potential for detailed analysis of what this coming home might mean.

The present situation is not the same as the past, but historians have been active in researching this past and in drawing out its implications for the present. This work has examined the interwar record of public health while located within local government (Gorsky, 2008). The historian Charles Webster's original critique of the record of public health in that era has been modified by more recent work, including that by Alysa Levene, Becky Taylor and John Stewart which has shown that public health did have its achievements (Webster, 1980; Levene, 2011). This research has shown vitality at the local level and how local circumstances could determine decisions about what expenditure there was on public health activity. There were variations in expenditure at the local level which suggest that room existed for local councils and officers to set priorities for spending according to local need within the constraints imposed by national and fiscal factors. Party politics may have determined those decisions at the local level, but it is clear that the role of key individuals pursuing policy objectives in local settings, was also important. A strong minded Medical Officer of Health $(\mathrm{MoH})$ working within political structures could achieve improved public health outcomes. That was the case even after World War II when public health occupied a more limited role after the formation of the NHS. Paddy Donaldson, the father of our former Chief Medical Officer, Sir Liam Donaldson, was one of the last MoHs in local government in the 1960s and operated effectively within the local government political system in Stockton on Tees in the north of England (Donaldson, 2000).

There is currently more cause for optimism in assessing interwar public health work. The newer interpretation argues that running health services was not a diversion for public health. Rather, it started to bring together preventive and curative services. The influence of a high profile local official, the $\mathrm{MoH}$, could be considerable. The annual health report brought together health statistics on the area. The $\mathrm{MoH}$ headed a well-staffed department with workers ranging from health visitors to sanitary inspectors.

Such work has obvious relevance to the present day where public health has once again come to rest 'come home' in local government. The situation is by no means the same but the likely issues, tactics and roles of public health personnel 
can all be informed by this history. The very fact that public health is once again operating within political rather than evidence-based structures should lead to a looking back to the past. Historians have drawn out conclusions, working with public health academics, and published in a public health journal. These focussed on the role of leadership; funding; communication; and vision and rationale. Public health leaders had the opportunity to shape an integrated service on the model of the pre-war local authority model (Gorsky et al., 2014). But not all agree and the published article led to debate from 'one who was there' who thought the move back to the local authorities was a retrograde one (Holland, 2015).

A further development of the history and policy relationship in this area came through a one day conference at LSHTM in May 2017 on the theme of devolution and transformation in the NHS. This was organised jointly with the IPPR (Institute for Public Policy Research) a think tank. Historians spoke about the history of local government services; and about the NHS and how it had originally been intended to be a local government based service. Current policy makers, including those involved in the DevoManc initiative, were involved in commenting on the historical papers and in presenting their perspective on present day matters. The audience included local government leaders and those responsible for health and social care in local authorities, interacting with the historical discussion. The potential variability of services at the local level which might result from local control was one area of concern: NHS centralisation, although cumbersome, could be a good development to achieve greater equity. The IPPR intends to produce a booklet from the day's events which it will circulate to its extensive network of policy makers and others.

\section{Britain as a 'hard drinking' society}

In this example, historical input took place in a different way. A few years ago, there was much public commentary about how Britain had always been a 'hard drinking society' - maybe the role of alcohol was something endemic to the British psyche - and by implication we did not need to worry too much about controls or reducing consumption. This type of historical argument was particularly attractive to the media and also to the alcohol industry.

The House of Commons Health committee held an enquiry into the subject and historians were asked to give evidence. It was shown through the historical evidence that the supposition about British drinking habits was quite wrong. There had been periods of heavy drinking but there had also from the late 19th century onward into the 1960s, been a period of decline in drinking and really quite low consumption. Britain had not always been a heavy drinking society and the issue was to tease out why consumption had started to rise. The committee like this deposition and put it into their final report as a separate chapter (House of Commons, 2017). 


\section{How other disciplines use history}

These are two recent examples in which historians have been involved. But they are not the only players. Here are some examples of the uses of history by others with policy interests.

\section{Lectures and teaching}

While writing a short book about public health and its history, I decided to attend some lecture courses at LSHTM to find out about current issues in public health. My colleagues were rather astounded by this, but I sat through the introduction to public health; models of health behaviour; climate change; infectious disease and so on. The Centre historians teach history to Masters students, but, to my surprise, these non-historian colleagues' lectures were also full of history. A lecture on public health talked about the evolution of the state from the Princely state of the late 15th century to the market state of more recent times. A lecture on infectious disease used William McNeil's work for what it termed a short history of man and bugs. Looking in general at the ways in which history was being used, I realised there was an emphasis on issues such as quarantine; health and 'the other'; and punitive responses, incarceration, and prostitutes and the Contagious Diseases Acts in the 19th century. History was being used by my colleagues to provide an object lesson in the importance of present day concerns about human rights and individual liberty, and served to illustrate the current mission of public health as it saw itself, as a force for good. There was none of the debate which would have characterised input from a professional historian. Anything which challenged the rosy view of public health was not there - there was nothing about the different potential missions of public health or the conflict between 'technical fixes' and wider action on inequality. This was history as confirmation of the current state of play rather than to encourage critical thinking. There were wider implications: this might be the history which my colleagues could be bringing into policy through external advisory roles.

Timelines have been another eye opener. There is currently great enthusiasm for these in the health field and digital developments make it possible to link to historical literature. A colleague and I recently advised one of our students who worked for a health funding charity developing a number of subject-based timelines. It was interesting to note that most of the links to secondary literature they had inserted were not to the work of historians - unless they had published in easily accessible health journals or in partnership with non-historians. Nor was there a clear definition in the case of public health, of what this area actually was.

There is thus an 'inhouse' received opinion health history which can be preferable both to colleagues and to policy makers. The role of John Snow, the public health epidemiologist who is said to have discovered the water borne spread of cholera, is the classic one for public health and exemplifies this stance. 
The epidemiological 'dot map' of Broad Street, the area in Soho, London where the outbreak occurred and the location of the pump whose handle he insisted on having removed, has been taught for decades as an epidemiology exercise to public health students. The main lecture theatre at LSHTM is the John Snow theatre, even though John Snow had nothing to do with the School and died well before it was established. Visitors are taken upstairs to see the John Snow pump, even though in fact the pump is a facsimile. When I gave a public lecture during which I pointed out how John Snow had assumed this 'heroic' status - basically to fit the needs of US epidemiology in the 1920s - I was not asked to give the lecture again in the following year's series (Vandenbroucke et al., 1991). More recently both lesbian and gay history and black history months have been organised almost without history but only with reference to current events, something we have changed by direct intervention.

\section{Scientific history}

There is also a particular style of using history which involves science rather than historical interpretation. The work of an historian on 'Patient Zero', the role of Gaetan Dugas, the airline steward whose promiscuity was said to have helped spread the initial HIV/AIDS epidemic among gay men, showed that his apparent culpability had been overestimated (McKay, 2011). But this only made headline news in the media when it was confirmed by science. Scientists showed that the virus had been circulating well before his time (The Guardian, 2017). This type of 'scientific history' attracts great external interest.

\section{Do it yourself history}

There is the expansion of 'do it yourself' history. 'Do it yourself' history has flourished in particular in the tobacco field because of the advent of the digitised industry archives and this tends to present a one dimensional picture which simply confirms existing stereotypes. At one stage, several of my colleagues working on tobacco control were doing archival research using digitised tobacco industry documents. They knew little of the historiography of what had already been published by historians in this field.

Digital history is likely to expand as a methodology more generally in the future in the health field as more material goes into this format or is 'born digital'. The emphasis on history as an interpretive discipline not just as 'the facts' in some senses makes this more problematic. Your interpretation based on digital sources or do it yourself research might been seen as having as much validity as mine. I was struck during a recent meeting in London of an international network on Museums, Medicine and Society when museum curators reported that in exhibitions they had organised community interpretations of historical events were 
given as much validity and prominence as those of professional historians. Given the fluidity of interpretation and its change, why not? they asked.

So there are many problems for historians in trying to make their voices heard. The field is a crowded one and their expert status is not always acknowledged.

\section{Having impact, where and how}

Having impact is an issue which has been much discussed in the world of evidence and policy. A research programme looked at this conundrum and also a series of interviews with policy makers of various types who had used history (Berridge, 2005, 2008). This section draws on these and also on the earlier case studies.

There are different levels of policy making. At the national level, high level politicians can be historically conscious. Winston Churchill and Gordon Brown were both Prime Ministers who wrote and used history. More recently Chancellor George Osborne was historically conscious and worked with historians. In the past, Labour politicians paid homage to the role of Aneurin Bevan as the founder of the NHS, or justified the introduction of hospital trusts by reference to the history of working class mutualism. Tony Blair as Prime Minister initially wanted everything to be presented as new, but as his term in office drew to a close, became increasingly reflective about the context in which he had been operating. Simon Stevens, current head of NHS England, recently spoke at the Kings Fund in London on proposed changes in local health service planning in a speech which was full of history. The tendency for 'do it yourself' history is as strong in policy circles as it is outside.

The public health and localism example cited above is putting historical input in at both the national but also the local level of policy making. There can be different entry points in different political systems.

Timing is key - something can be of little interest at one stage, centre stage a few months or a year later. A colleague who had published a major book on alcohol lamented that it came too early for the revived government interest in the subject (although he could have done something with that).

Alliances and networks are also important - in the British structure until recently at least civil servants were key players and some had been in post long term and really knew their areas. However, the civil service in particular in the health area has changed and shrunk in recent years and many long serving bureaucrats have left, taking with them a loss of institutional memory. In the alcohol example I used, the evidence was highlighted in part because both of the civil servants connected with the committee were historians.

In the British system, academics also act as expert advisers in some areas of health and these provide a boundary mechanism for contact. Work with other disciplines or occupations can be important. Tony Blair was a great user of policy discussion groups and 'the historian' on those could be a journalist historian such as Nick Timmins who has written widely on health and social care. 
Such 'boundary figures' are important mediators of history. Other examples are the journalist historian Peter Hennessy, who does not write on health but who has made a long-standing analysis and has involvement in British policy structures. James Nicholls, a former academic who is now research director of an alcohol funding charity, fulfils a similar history/policy boundary role in the alcohol field. Such 'journalist historians' have the ability to frame a message effectively, admittedly not always the professional historian's forte. Historically attuned civil servants can likewise reframe a message in policy terms. In the health arena, nursing policy specialist Ann Marie Rafferty is also an historian by background and uses her historical training in her policy analysis.

\section{Should historians be advocates?}

Unlike other disciplines in the social sciences which tend to like to label and categorise matters, historians like to understand and make sense of complexity. That process, by its very nature, is not one which makes a direct policy case the most natural outcome. Historians' work, we tell our students, is there 'to make you think', to open up options. A speech writer I interviewed commented that politicians liked historians because they did not tell them what to do - which most other advisers from a disciplinary background did.

But there are clearly different views on this - and also different national cultures of impact. A notable instance of this is in the United States with its greater reliance on the law court to decide policy. Historians have acted as 'expert witnesses' taking one side or other in law suits, as for example in cases round industrial health and safety with work by Rosner and Markowitz and also in particular in relation to the cigarette industry. Allan Brandt's book Cigarette Century did not start as a contribution to a legal case but much of the final work which was published was part of the law suit - indeed it was difficult not to take this route in the US situation (Brandt, 2007).

More recently, Robert Proctor's Golden Holocaust has used history to call for complete prohibition of tobacco-apparently unaware of some of the historiography around alcohol prohibition (Proctor, 2011). The cover of the book and its subtitle 'Origins of the Cigarette Catastrophe and the case for abolition' says it all. Proctor's argument is that the cigarette must be eliminated, and that as a first step the FDA must reduce the nicotine content of cigarettes (to lower their 'addictive grip') and require that no cigarette produce smoke with a ph lower than 8 (to make the smoke un-inhalable). The dangers and lessons of US alcohol prohibition are brushed aside.

This is a very American type of smoking history, with its 'heroes and villains' US focussed approach. It reads like a detailed journalist expose - with a tendency to roam widely in terms of time in each section and even chapter. US smoking history (in both the anti and pro camps) has proceeded in a very particular way - via the law court. This has not been the norm in other countries. The involvement of US 
historians in these cases has brought with it a particular way of writing history. It is what Proctor himself terms 'lopsided and biased' because that type of testimony is what the law court requires. Historians have to make a case in a different way to the normal mode of historical analysis. Some might argue that the US law court style of using history is 'neo Whig', looking at history from 'the wrong end of the telescope'. It confirms the present stance rather than seeking to question or understand it. However, it can be a powerful force for change. In the United Kingdom, some historians in policy positions also use history for advocacy although rarely through the law courts. The use of history in current nursing policy is a particular example.

The political science literature about the relationship between evidence and policy identifies a multitude of different ways in which evidence can impact on policy (Berridge, 2005). History can have a very direct impact, sometimes through the law courts. But in the British culture which has little recourse to law in these instances, it is more likely to be a seeping through into discussion and debate at different entry points in the system. The function of history can be a gradual one, to widen horizons and alter the terms of the debate. The current analysis of health and social care and public health in local government is one example of that approach.

But of course we have to recognise too that our conclusions, however well honed, may not fit the 'narrative of policy' or the assumptions of our colleagues. History, when it is drawn upon, is not entering a policy vacuum but is one among many levers of policy. That policy process is messy and chaotic, subject to many influences. Those who have investigated the relationship between evidence and policy recognise this and historians too have to be realistic. Political imperatives of one type or another will always come first. And people in the field like stereotypes from history. In my own work, I have found the view that 'Queen Victoria used cannabis,' (and hence by implication it is a harmless drug) difficult to challenge. Sometimes also the 'wrong history' is used and it is not helpful. In the 2009 swine flu outbreak in England for example, history was discussed and drawn upon. But the example used was that of the 1918 influenza pandemic which killed millions worldwide. It was subsequently concluded in a government report that overreaction and risk communication had been problems during the outbreak, hardly helped by this apocalyptic history (GOV.UK, 2017a).

\section{Conclusions}

History is a discipline which should be at the policy table and can add dimensions which others cannot. It can give an overview of the complexity of policy issues and their change over time; other social science disciplines tend to label and categorise, to neaten things up, or to deal with small sections of an issue. There are many misunderstandings current about history, in particular the reputation of historians as 'worker bees' providing the facts for a more elevated discussion by other 
disciplines. History can provide input, as this paper has shown, in a number of different ways, through the law courts in some cultures; as a statistical 'magic bullet' disproving long held beliefs; or in a more diffuse way, gradually changing and enlarging the terms of the public and policy debate. It cannot do that by itself - it needs alliances and networks and in particular 'boundary allies' who operate in both history and policy worlds. It need not be taken over by current events - the historian's powers of cool analysis are forward looking enough.

\section{Acknowledgement}

I am grateful to Professor Gregory Marchildon for his comments on the paper and also to the anonymous referees who commented. Their suggestions have greatly improved it. I am also grateful to the organisers of the AMS anniversary conference in Toronto at which this paper was originally delivered.

\section{References}

Berridge, V. (2005), Making Health Policy: Networks in Research and Policy After 1945, Amsterdam: Brill.

Berridge, V. (2008), 'History matters? History's role in health policy making', Medical History, 52(3): 311-326.

Berridge, V. (2010), 'Thinking in time: does health policy need history as evidence?', Lancet (London, England), 375(9717): 798-799.

Berridge, V. and T. Hickman (2007), 'History and the Future of Psychoactive Substances', in D. Nutt, T. W. Robins, G. V. Stimson, M. Ince and A. Jackson (eds), A Drugs and the Future: Brain Science, Addiction and Society, London: Elsevier.

Berridge, V. and A. Mold (2016), 'Regulation and Culture: Learning from the History of Smoking and Alcohol', In Joint Essay Collection by the All-Party Parliamentary Health Group and the Health Foundation.

Brandt, A. M. (2007), The Cigarette Century: The Rise, Fall, and Deadly Persistence of the Product That Defined America, New York: Basic Books.

Centre for History in Public Health (2014), 'Local and National Alcohol Policy: How Do They Interact?', https://blogs.lshtm.ac.uk/history/files/2015/01/Alcohol_seminar_report_ December_2014.pdf [12 December 2017].

Donaldson, R. J. (2000), Off the Cuff: Reminiscences of My Half Century Career In Public Health, Richmond, Surrey: Murray.

Gorsky, M. (2008), 'Public health in interwar England and Wales: did it fail?', Dynamis (Granada, Spain), 28: 175-198.

Gorsky, M., K. Lock and S. Hogarth (2014), 'Public health and English local government: historical perspectives on the impact of "returning Home", Journal of Public Health (Oxford, England), 36(4): 546-551.

GOV.UK (2017a), 'Independent Review into the Response to the 2009 Swine Flu Pandemic', https://www.gov.uk/government/publications/independent-review-into-the-response-tothe-2009-swine-flu-pandemic [12 December 2017].

GOV.UK (2017b), 'No 10 Guest Historian Series, History of Government', https://history. blog.gov.uk/category/no-10-guest-historian-series/ [12 December 2017]. 
Green, A. R. (2016), History, Policy and Public Purpose: Historians and Historical Thinking in Government, London: Palgrave Macmillan.

The Guardian (2017), 'Gaétan Dugas: "Patient Zero” Not Source of HIV/Aids Outbreak, Study Confirms, Science', https://www.theguardian.com/science/2016/oct/26/patientzero-gaetan-dugas-not-source-of-hivaids-outbreak-study-proves [8 March 2017].

Guldi, J. and D. Armitage (2014), The History Manifesto, Cambridge University Press.

History and Policy (2016, August 3), http://www.historyandpolicy.org/ [12 December 2017].

Holland, W. W. (2015), 'Public health coming home', Journal of Public Health, 37(2): 362-363.

Horton, R. (2014), 'The Moribund body of medical history', The Lancet, 384(384): 292.

House of Commons (2017), 'Alcohol - Health Committee', https://www.publications. parliament.uk/pa/cm200910/cmselect/cmhealth/151/15106.htm [17 May].

Levene, A. ed. (2011), Cradle to Grave: Municipal Medicine in Inter-War England and Wales Studies in the History of Medicine, Volume 4 Oxford: Peter Lang.

McKay, R. A. (2011), 'Imagining "Patient Zero": Sexuality, Blame, and the Origins of the North American AIDS Epidemic", Oxford: Oxford University Press.

Neustadt, R. E. and E. R. May (1986), Thinking in Time: The Uses of History for DecisionMakers, New York, London: Free Press, Collier Macmillan.

Porter, D. H. (1981), The Emergence of the Past: A Theory of Historical Explanation, Chicago, London: University of Chicago Press.

Proctor, R. (2011), Golden Holocaust: Origins of the Cigarette Catastrophe and the Case for Abolition, Berkeley: University of California Press.

Results \& Submissions: REF 2014 (2017), 'Impact (REF3a/B)'. http://results.ref.ac.uk/ Submissions/Impact/1426 [8 March 2017].

Tosh, J. (2008), Why History Matters, Houndmills, Basingstoke, Hampshire: Palgrave Macmillan.

Vandenbroucke, J. P., H. M. Eelkman Rooda and H. Beukers (1991), 'Who made John Snow a hero?', American Journal of Epidemiology, 133(10): 967-973.

Webster, C. (1980), 'Healthy or hungry thirties?', The Society for the Social History of Medicine Bulletin, 27: 22-24. 